return to the patient and determine to what extent the findings derived from in vitro studies are directly applicable to the human condition.

\footnotetext{
References

Danes, B.S. \& Bearn, A.G. (1966a) Hurler's syndrome. A genetic study in cell culture. $J$. exp. Med. 123, 1 .

DANES, B.S. \& BEARN, A.G. (1966b) Hurler's syndrome. Effect of retinol (vitamin A alcohol) on cellular mucopolysaccharides in cultured human skin fibroblasts. J. exp. Med. 124, 1181.
}

DANes, B.S. \& BEARN, A.G. (1967) The effect of retinol (vitamin A alcohol) on urinary excretion of mucopolysaccharides in the Hurler syndrome. Lancet, i, 1029.

Henderson, J.L. (1940) Gargoylism; review of principal features with report of five cases. Arch. Dis. Child. 15, 215.

McKusick, V.A. Heritable Disorders of Connective Tissue. Mosby, St Louis.

SAto, A. (1955) Chediak and Higashi's disease. Probable identity of 'a new leucocytal anomaly (Chediak)' and 'congenital gigantism of peroxidase granules (Higashi).' Tohoku J. exp. Med. 61, 201.

White, J.G. (1966) The Chediak-Higashi syndrome: A possible lysosomal disease. Blood, 28, 143.

\title{
Enteropoiesis: structural and functional relationships of the
}

\section{enterocyte}

\author{
C. C. Воотн
}

Royal Postgraduate Medical School, London

The Remarkable turnover of the cells of the intestinal mucosa was first suspected by Bizzozero as long ago as 1888 and has been firmly established by modern techniques during the past 20 years (Leblond \& Stevens, 1948; Leblond \& Messier, 1958 ; Creamer, Shorter \& Bamforth, 1961). The absorbing cells of the small intestine have, as Smyth has pointed out, a 'short life and a merry one ... if merriment is the equivalent in cellular terms of a remarkable range of activities possessed by few other cells in the body' (Smyth, 1967). Formed in the crypts of Lieberkuhn, the intestinal cells are extruded on to the surface of an adjacent villus whose side they climb until they reach the villus tip, from where they are shed into the intestinal lumen. The total turnover time for the cells of the jejunum is known to be as rapid as 2 or 3 days in the mouse and perhaps 5 days in man (MacDonald, Trier \& Everett, 1964 ; Shorter et al., 1964), so that the body only uses the extraordinary biological activities of these cells for a very brief period.

Doniach \& Shiner (1960) were the first to draw the analogy between the intestinal epithelial cells and the haemopoietic system. They compared the germinative or crypt zone, where the cells are manufactured, with the erythroblasts of the bone marrow and the adult absorbing cells of the villi with the erythrocytes of the peripheral blood. Doniach \& Shiner pointed out that in coeliac disease, where the jejunal mucosa is devoid of villi but the glandular or germinative layer of the small intestine is markedly increased, 'the situation is comparable with anaemia in which there is reduction of the peripheral red cells (villous cells) and compensatory hypertrophy of the red bone marrow (glandular mucosa)'.

This paper explores further the theoretical possibilities raised by Doniach's haematological analogy and suggests a new nomenclature for the intestinal mucosal cells. The functional implications of this classification are also discussed.

\section{Nomenclature of the intestinal absorbing cells}

There are a variety of different cell types present in the intestinal mucosa. Paneth cells, argentaffin cells and goblet cells mingle with the columnar cells which make up the major part of the absorptive epithelium and which are the concern of this paper. These columnar cells have been given a variety of names such as villous cells, absorptive cells, mucosal surface cells and adult epithelial cells, and the cells in the crypts of Lieberkuhn have been variously called the glandular cells, germinative zone or production zone. The use of a haematological analogy suggests a more satisfactory nomenclature which at the same time links the formative cells of the crypts with their adult counterparts. If the absorptive cell on the surface of the villus is given the term 'enterocyte', then the germinative cell in the glandular mucosa should be called an 'enteroblast', the function of this cell being 'enteropoiesis'. The further implications of this 
nomenclature are shown schematically in Fig. 1. The enterocyte may be enlarged (a macroenterocyte), normal, or reduced in size (a microenterocyte). The numbers of the enterocytes may be increased (enterocytic hyperplasia), normal or reduced (enterocytic hypoplasia). Furthermore, the function of the enterocyte is not static for under certain circumstances there may be either increased or decreased function of this cell. Defining the intestinal cell in this way poses a number of questions which can only be resolved by future research, but recent studies have already demonstrated many of the situations shown in Fig. 1.

\section{The macrocytic enterocyte}

In pernicious anaemia it is well known that the cells of the buccal mucosa may be larger than normal. Similarly in the small intestine a recent report has described macrocytic enterocytes and a megaloblastic enteroblast (Foroozan \& Trier, 1967). This appears to be associated with enterocytic hypoplasia since there is also shortening of the villi. How such cells function is not known. The cause of the intestinal abnormality in pernicious anaemia is presumably a similar 'maturation arrest', involving the enteroblast, to that seen in the bone marrow.

As might be expected an arrest of cell turnover in the small intestine also occurs after $\mathrm{X}$-irradiation. A recent study of jejunal biopsies obtained from patients undergoing therapeutic $X$-irradiation (Trier \& Browning, 1966) has demonstrated that the mitoses in the enteroblastic layer of the small intestine are reduced within $12 \mathrm{hr}$ of starting X-ray therapy. Thereafter, there is enterocytic hypoplasia, causing marked shortening of the villi and at the same time megaloblastosis and megalocytosis of the epithelial cells develops. As in pernicious anaemia, this situation is rapidly reversible.

The question must also be asked whether the enterocyte may become macrocytic when there is compensatory hypertrophy following partial resection of the small intestine. Although there is clear evidence of enterocytic hyperplasia after intestinal resection, macrocytic enterocytes have not hitherto been encountered in this situation.

\section{The normocytic enterocyte}

As indicated in Fig. 1, the normocytic enterocyte may be normoplastic, hyperplastic or hypoplastic, and its function may be increased, normal or decreased.

\section{(i) Normoplasia}

Clearly the normal situation in the small intestine is established when there are normocytic enterocytes which are present in 'normal' numbers and which function 'normally'. As with all other biological phenomena, however, there is a considerable range of normality in the small intestine. There are marked variations in the number of enterocytes which constitute normality and these variations are reflected by differences in the appearance of the surface mucosa in different individuals and in different populations throughout the world. Under the dissecting microscope, the shapes of the villi of the small intestine vary widely, some individuals showing villi which are entirely finger-shaped, whereas others have a pattern of leaf- and tongueshaped villi. Creamer (1964) has estimated that the number of enterocytes required to cover leaf-shaped villi are only $25 \%$ of those necessary when the villi are finger-shaped. The variation in the number of enterocytes in different normal individuals is not surprising in an organ where cell turnover is extremely rapid and where the balance between enteropoiesis and cell loss must often be precarious.

Increased function of normocytic enterocytes may occur in a variety of situations of stress. The effects of bulk-feeding in the rat provide an interesting example of hyperfunction (Dowling et al., 1967a). When the diet of the animal contains a large amount of unabsorbed bulk, there is an increase in the absorptive capacity of the small intestine without any change in the macroscopic appearance of the bowel and without enterocytic hyperplasia. Using the everted sac technique Dowling et al. (1967a) showed that glucose absorption by the jejunum of rats whose diets contained $60 \%$ or $80 \%$ by weight of

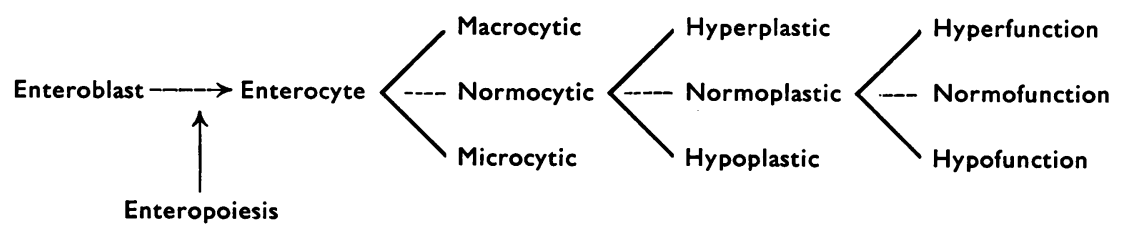

FIG. 1 
powdered kaolin was $4.81( \pm 0.99 \mathrm{SEM}) \mathrm{mg}$ and $9.96( \pm 0.53$ SEM) $\mathrm{mg}$ respectively per $100 \mathrm{mg}$ dried intestinal tissue per hour, compared with $2.52( \pm 0.66 \mathrm{SEM}) \mathrm{mg}$ in control rats. Detailed anatomical and histological studies showed that this functional response was not due to any increase in absorptive surface area. However, there was an increased activity of certain enzymes in the enterocytes (Riecken et al., 1965) suggesting that the enhanced absorption may be related to increased activity of the individual mucosal cells. This contrasts with the situation following intestinal resection, when, as described below, enterocytic hyperplasia alone appears to be the adaptative response.

Decreased function of normocytic enterocytes may be either congenital or, less frequently, acquired. The hereditary abnormalities of intestinal absorption (Milne, 1967), such as the rare condition of glucose/galactose malabsorption, the much more common hereditary deficiency of disaccharidases (alactasia for example), the absorption defect for aminoacids in cystinuria or the hereditary defect of vitamin $B_{12}$ absorption described by Imerslund (1960) and Gräsbeck et al. (1960) are all examples of congenital decrease of the function of normocytic enterocytes.

Acquired and transient defects in enterocytic function have been described in acute gastroenteritis (King \& Joske, 1960) or after neomycin administration (Reiner \& Patterson, 1966).

\section{(ii) Hyperplasia}

After partial resection of the small intestine there is an increase in enteropoiesis (Loran \& Althausen, 1960) and this results in enterocytic hyperplasia. In man, for example, Porus (1965) found an increase in the number of enterocytes in the midzone of the villus in two out of four patients who had undergone resection of part of the small intestine, although the villi appeared to be normal in height in these two individuals. Dowling \& Booth (unpublished data) have also demonstrated enterocytic hyperplasia after small intestinal resection in man and have found enlargement of the villi. In jejunal biopsies obtained from twelve patients who had been subjected to partial resection of the small intestine, the mean villus height was $440 \mu( \pm 16$ SEM) compared to a mean of $382 \mu( \pm 20$ SEM) in eleven matched control subjects, the difference being statistically significant $(P<0.05)$. This enterocytic hyperplasia was associated with an increase in the functional capacity of the small intestine. Using a $21 \mathrm{~mm}$ glucose solution, absorption of glucose was compared in a $25 \mathrm{~cm}$ segment of jejunum in control subjects and in patients with intestinal resection. Eight of the patients in whom resection had been performed absorbed 60.9 $( \pm 2.20$ SEM) $\mathrm{mg}$ of glucose per $25 \mathrm{~cm}$ of intestine per minute, as compared with $48.3( \pm 2.07$ SEM) $\mathrm{mg}$ in the control subjects (Dowling \& Booth, 1966).

More direct observations on the relationship between enterocytic hyperplasia and increased intestinal function have been made in the rat (Dowling \& Booth, 1967). In this animal, there is a different response to proximal and distal small bowel resection. When the jejunum is removed, the residual ileum shows marked enterocytic hyperplasia and the height of the villi increases by more than $50 \%$. After ileal resection, however, the enterocytes of the jejunal remnant are less markedly hyperplastic and the villus height only increases by $10-15 \%$. The functional response is directly related to the degree of enterocytic hyperplasia, for studies of glucose absorption in animals subjected to such resections demonstrate that there is an increase in intestinal function per unit length of intestine which shows a highly significant correlation with the amount of increase in villus height (Dowling \& Booth, 1967). In other words, when there is enterocytic hyperplasia following partial resection of the small intestine, the increase in intestinal function is a result of an increase in the number of enterocytes and not of any increase in the function of the individual intestinal mucosal cells. The absence of any functional change in the individual enterocyte is supported by the observation that the mucosal cell enzymes do not increase in this situation (Dowling, Riecken \& Booth, 1967b), in striking contrast to the increase in enzymes demonstrated in animals after high-bulk feeding which has already been described.

\section{(iii) Hypoplasia}

Hypoplastic normocytic enterocytes have been demonstrated in the small intestine where there is malnutrition. In monkeys with experimental kwashiorkor, for example, there is an overall reduction in enteropoiesis. The enteroblastic layer is reduced in thickness and the villi are shorter than normal (Deo \& Ramalingaswami, 1965). This has been shown by ${ }^{3} \mathrm{H}$-thymidine labelling to be associated with a decreased turnover of the intestinal mucosal cells. Similar observations had been made in rats subjected to starvation (Stevens Hooper \& Blair, 1958).

\section{The microcytic enterocyte}

Microcytic enterocytes are found either when 
there is some factor damaging and destroying the enterocyte, a condition analagous to haemolysis, or occasionally when there is inhibition of enteropoiesis. Microcytic enterocytes are invariably associated with hypoplasia and hypofunction.

\section{(i) Factors damaging the enterocyte}

The most striking example of the microcytic enterocyte is seen in coeliac disease. In this condition, the enterocytes are markedly reduced in height and electron microscopy reveals intracellular disorganization and severe disruption of the microvillous border of the cell. There is a gross reduction in the number of enterocytes so that the villi disappear and the mucosa is frequently flat and featureless. At the same time, overall enteropoiesis appears to be increased, for in contrast to the situation following $X$-ray therapy or in malnutrition, the enteroblastic layer is markedly thickened and there is an increase in mitotic activity within the crypts. The available evidence suggests that the dietary constituent, gluten, is toxic to the enterocyte, damaging and destroying it, and enteropoiesis is therefore accelerated in an attempt to keep pace with the greatly increased loss of enterocytes. The reason why the enterocyte should be so susceptible to damage by gluten is not yet known, but to pursue the haematological analogy further, the situation is not unlike the haemolysis caused by the dietary toxin, fava beans, when an individual is deficient in glucose-6-phosphate dehydrogenase. It has therefore been postulated that coeliac disease may be due to a hitherto unknown enzyme defect in the enterocyte, a hypothesis which is supported by the observation that the disease may be genetically determined (MacDonald, Dobbins \& Rubin, 1965).

\section{(ii) Factors inhibiting enteropoiesis}

When enteropoiesis is inhibited by $\mathrm{X}$-irradiation, or in pernicious anaemia, the enterocytes develop macrocytosis. There are, however, other situations in which ineffective enteropoiesis results in the development of small and ineffective enterocytes. Folic acid antagonists such as aminopterin are effective inhibitors of enteropoiesis and cause marked enteroblastic and enterocytic hypoplasia in experimental animals. Providing that the dose of aminopterin is sufficiently low to permit recovery, the enterocytes may demonstrate marked microcytosis during the recovery phase (see Fig. 11A and B, Zamchek, 1960).

\section{Conclusion}

Enterologists usually approach the problems of the small intestine by feeding measured amounts of various substances and then estimating how much is excreted. Such balance experiments measure the overall function of a highly complex organ and have provided a great deal of valuable information in the past. It is now possible, however, to study intestinal function at a cellular level so that the overall function of the organ may be expressed in cellular terms. By the use of haematological analogy, a new terminology has been developed to describe the relationship between structure and function in the small intestine which may be of value to future research.

\section{Acknowledgments}

I wish to thank my colleagues in the gastroenterology group at Hammersmith for many interesting and instructive discussions, and Professor Sir John McMichael for his constant support and encouragement.

\section{References}

Creamer, B. (1964) Variations in small intestinal villous shape and mucosal dynamics. Brit. med. J. ii, 1371.

Creamer, B., Shorter, R.G. \& Bamforth, J. (1961) The turnover and shedding of epithelial cells. 1. The turnover of the gastrointestinal tract. Gut, 2, 110.

Deo, M.G. \& Ramalingaswami, V. (1965) Reactions of the small intestine to induced protein malnutrition in Rhesus monkeys-a study of cell population kinetics in the jejunum. Gastroenterology, 49, 150.

Doniach, I. \& Shiner, M. (1960) Histopathology of the stomach in pernicious anaemia and jejunum in steatorrhoea. Brit. J. Radiol. 33, 238.

Dowling, R.H. \& Booth, C.C. (1966) Functional compensation after small bowel resection in man. Lancet, ii, 146.

Dowling, R.H. \& Booth, C.C. (1967) Structural and functional changes following small intestinal resection in the rat. Clin. Sci. 32, 139.

Dowling, H., Riecken, E.O., Laws, J.W. \& Booth, C.C. (1967a) The intestinal response to high bulk feeding. Clin. Sci. 32, 1.

Dowling, R.H., Riecken, E.O. \& Booth, C.C. (1967b) The morphological and histochemical response to small bowel resection in the rat. (In preparation).

Foroozan, P. \& TRIER, J.S. (1967) The small intestinal lesions in pernicious anaemia. Gasteroenterology, 52, 1085.

Gräsbeck, R., Gordin, R., KANTERo, I. \& KUHLbÄCK, B. (1960) Selective vitamin $B_{12}$ malabsorption and proteinuria in young people. Acta med. scand. 168, 289.

IMERSLUND, O. (1960) Idiopathic chronic megaloblastic anaemia in children. Acta paediat., Stockh. 49, Suppl. 119.

KING, M.J. \& JosKe, R.A. (1960) Acute enteritis with temporary intestinal malabsorption. Brit. med. J. i, 1324.

Leblond, C.P. \& Messier, B. (1958) Renewal of chief cells and goblet cells in the small intestine as shown by radioautography after injection of thymidine- ${ }^{3} \mathrm{H}$ into mice. Anat. Rec. 132, 247.

Leblond, C.P. \& Stevens, C.E. (1948) Constant renewal of intestinal epithelium in albino rats. Anat. Rec. 100, 357.

Loran, M.R. \& Althausen, T.L. (1960) Cellular proliferation of intestinal epithelia in the rat two months after partial resection of the ileum. J. biophys. biochem. Cytol. 7, 667.

MacDonald, W.C., Dobbins, W.O. \& Rubin, C.E. (1965) Studies of the familial nature of celiac spure using biopsy of the small intestine. New Engl. J. Med. 272, 448. 
MacDonald, W.C., Trier, J.S. \& Everett, N.B. (1964) Cell proliferation and migration in the stomach, duodenum and rectum of man: radioautographic studies. Gastroenterology, 46, 405.

MiLne, M.D. (1967) Hereditary abnormalities of intestinal absorption. Brit. med. Bull. 23, 279.

PoRUs, R.L. (1965) Epithelial hypoplasia following massive small bowel resection in man. Gastroenterology, 48, 753.

Reiner, E. \& PAtTerson, H. (1966) The effects of neomycin on disaccharidase activity of the small bowel. Clin. Res. 14, 499.

Riecken, E.O., Dowling, H., Booth, C.C. \& Pearse, A.G.E. (1965) Histochemical changes in the rat small intestine associated with enhanced absorption after high bulk feeding. Enzymol. biol. clin. 5, 231.
Shorter, R.G., Moertel, C.B., Titus, J.L. \& Reitemeier, R.J. (1964) Cell kinetics in the jejunum and rectum of man. Amer. J. digest. Dis. 9, 760.

SмYтH, D.H. (1967) Intestinal absorption. Brit. med. Bull. 23, 207.

Stevens Hooper, C. \& Blair, M. (1958) The effect of starvation on epithelial renewal in the rat duodenum. Exp. Cell Res. 14, 175.

Trier, J.S. \& BrownING, T.H. (1966) Morphological response of the mucosa of human small intestine to $\mathrm{X}$-ray exposure. J. clin. Invest. 45, 194.

ZAMCHEK, N. (1960) Dynamic interaction among body nutrition, gut mucosal metabolism and morphology and transport across the mucosa. Fed. Proc. 19, 855.

\title{
Distribution of diffusing capacity in obstructive lung disease
}

\author{
William A. BRiscoe \\ Columbia Medical Division of Bellevue Hospital; Department of Medicine, \\ College of Physicians and Surgeons, Columbia University, New York City
}

While I was a registrar at Hammersmith, Professor McMichael remarked one day, 'Why don't you do something about emphysema?' This led to my introduction to McMichael's method.

\section{McMichael's method}

It is sometimes forgotten that McMichael was initially best known in the field of respiration rather than circulation. In 1939, he described his new closed-circuit spirometer for measuring the functional residual capacity of the lungs (McMichael, 1939). The four novel features he introduced, partly in collaboration with Herrald (Herrald \& McMichael, 1939), were: (1) the maintenance of constant volume in the spirometer, from which a patient breathed for many minutes by adding oxygen at a rate equal to its metabolic consumption; (2) a pump was used to circulate and mix the gases rapidly in the spirometer; (3) the re-breathing period was prolonged beyond the usual $7 \mathrm{~min}$, when the patient's lungs mixed slowly with the gas in the spirometer ; and (4) an insoluble inert gas, hydrogen or helium, was used as the indicator, and estimated by its thermal conductivity. These innovations resulted in what is still, 28 years later, the best and most widely used method; it should perhaps be more widely referred to as McMichael's Method (Briscoe, 1965).

\section{Bad mixing}

Herrald \& McMichael (1939) had emphasized that in some patients, the mixing of inert gases between lungs and spirometer took much longer than normal. This had been a technical bugaboo in previous methods of lung volume measurement. It now seemed worth while to study this source of technical error as an interesting and perhaps important aspect of pathophysiology. The conclusions from this Hammersmith work were: normal lungs mixed helium from the McMichael spirometer as if they were nearly evenly ventilated. In patients incapacitated by bronchitis and emphysema, the behaviour of the lung could be almost exactly simulated by a simple two-chamber model, composed of two differently ventilated bellows or balloons in parallel. The well-ventilated bellows was small with a volume of about 1 litre, and ventilated by about $450 \mathrm{ml}$ breath. The poorly ventilated bellows was large with a volume of 3-5 litres, and ventilated by only $50 \mathrm{ml}$ breath (Briscoe, Becklake \& Rose, 1951 ; Briscoe, 1952; Briscoe \& McLemore, 1952). A lung of this type, with a normal volume of conducting airways, behaves as if it had a large physiological dead spacea simpler but less complete description of the real state of affairs.

We were not the only ones to recognize that uneven ventilation was the key to understanding the disturbance of function in obstructive lung disease: in the United States, Robertson, Siri \& Jones (1950) and Fowler, Cornish \& Kety (1952) published their classic studies of the distribution 